\title{
Adsorption Properties of Typical Lung Cancer Breath Gases on Ni-SWCNTs through Density Functional Theory
}

\author{
Qianqian Wan, ${ }^{1}$ Yancheng Xu, ${ }^{1}$ and Xiaoxing Zhang ${ }^{2}$ \\ ${ }^{1}$ Department of Endocrinology, Zhongnan Hospital of Wuhan University, Wuhan 430071, China \\ ${ }^{2}$ State Key Laboratory of Power Transmission Equipment \& System Security and New Technology, Chongqing University, \\ Chongqing 400044, China
}

Correspondence should be addressed to Xiaoxing Zhang; xiaoxing.zhang@outlook.com

Received 9 May 2017; Revised 5 July 2017; Accepted 13 July 2017; Published 17 September 2017

Academic Editor: Mo Yang

Copyright (c) 2017 Qianqian Wan et al. This is an open access article distributed under the Creative Commons Attribution License, which permits unrestricted use, distribution, and reproduction in any medium, provided the original work is properly cited.

\begin{abstract}
A lot of useful information is contained in the human breath gases, which makes it an effective way to diagnose diseases by detecting the typical breath gases. This work investigated the adsorption of typical lung cancer breath gases: benzene, styrene, isoprene, and 1-hexene onto the surface of intrinsic and $\mathrm{Ni}$-doped single wall carbon nanotubes through density functional theory. Calculation results show that the typical lung cancer breath gases adsorb on intrinsic single wall carbon nanotubes surface by weak physisorption. Besides, the density of states changes little before and after typical lung cancer breath gases adsorption. Compared with single wall carbon nanotubes adsorption, single $\mathrm{Ni}$ atom doping significantly improves its adsorption properties to typical lung cancer breath gases by decreasing adsorption distance and increasing adsorption energy and charge transfer. The density of states presents different degrees of variation during the typical lung cancer breath gases adsorption, resulting in the specific change of conductivity of gas sensing material. Based on the different adsorption properties of Ni-SWCNTs to typical lung cancer breath gases, it provides an effective way to build a portable noninvasive portable device used to evaluate and diagnose lung cancer at early stage in time.
\end{abstract}

\section{Introduction}

Recently, the morbidity and death rate of lung cancer has been one of the most serious cancer, which greatly threaten the human's life and health [1]. According to the global statistics data released by International Agency for Research on Cancer of the World Health Organization [2], there were 14.1 million new cancer cases, 8.2 million cancer deaths, and 32.6 million people living with cancer (within 5 years of diagnosis) in 2012 worldwide. Among them, the lung cancer case and mortality reached 1.8 million and 1.5 million. In addition, the lung cancer case and mortality have been rapidly increasing with the environmental pollution caused by modern urbanization and industrialization [3]. Although early diagnosis of lung cancer can effectively improve the cure rate of lung cancer [4], the big size, high detection price, and complex detection process of current armamentarium, make it hard for early diagnosis in time to be popularized, missing the best time to find and cure lung cancer.
Breath gases detection is one novel noninvasive diagnostic method with distinct advantages in convenience, safety, and noninvasion compared to traditional detection methods [5], making it a possible way to diagnose lung cancer by analyzing the gas composition and concentration of breath gases [6]. And breath gases detection method has been widely studied due to the great potential of application in screening and early diagnosis of cancer [7]. Phillips et al. proposed the idea using breath gases to diagnose lung cancer and screen out typical lung cancer breath gases $[8,9]$. Currently, the methods used to analyze the VOCs of breath gases for lung cancer detection include proton-transfer reaction mass spectrometry (PTR-MS) [10], selected ion flow tube mass spectrometry (SIFT-MS) [11], gas chromatographymass spectrometry (GC-MS) [12], and optical spectroscopy [13]. However, the shortcomings of the equipment, such as high price, slow speed, and poor portability, prevent its popularization. To overcome these shortcomings, gas sensors based a noninvasive portable device could be an effective 
way to diagnose lung cancer at early stage in time with the improvement of gas sensor's detection accuracy and chemical stability [14]. And nanomaterial is one of the most used materials used to prepare gas sensors due to its special electrical, chemical, and physical properties. It shows high sensitivity and selectivity to typical lung cancer breath gases by different material modification.

Because of the large specific surface area, small tip ratios, and high conductivity of carbon nanotubes, it has been widely used in the industrial, environmental, and medical detection as gas sensor [15]. Previous studies showed that SWCNTs are highly sensitive to most molecules upon functionalization. $\mathrm{Lu}$ et al. achieved the detection limit of $6 \mathrm{ppm}$ for $\mathrm{CH}_{4}$ using Pd-doped carbon nanotubes [16]. Penza et al. raised the detection limit of $\mathrm{NO}_{2}$ and $\mathrm{NH}_{3}$ to $100 \mathrm{ppb}$ and $5 \mathrm{ppm}$ with $\mathrm{Au}$ and $\mathrm{Pt}$ separately doped into carbon nanotubes [17]. Meng's group fabricated a new electrode using Pddoped SWCNT hybrid nanostructure for the nonenzymatic electrochemical detection of glucose [18]. In addition, $\mathrm{Ni}$ doping method has been one of most useful methods to enhance the gas sensing properties of materials. For instance, various previous studies have reported about its application in common environmental gases detection, including theoretical and experimental studies [19-22], while, until now, there is no study on Ni-SWCNTs sensors used to detect lung cancer by breath gases. In this study, we propose a novel way to detect typical breath gases of lung cancer: benzene $\left(\mathrm{C}_{6} \mathrm{H}_{6}\right)$, styrene $\left(\mathrm{C}_{8} \mathrm{H}_{8}\right)$, isoprene $\left(\mathrm{C}_{5} \mathrm{H}_{8}\right)$, and 1-hexene $\left(\mathrm{C}_{6} \mathrm{H}_{12}\right)$ by theory computation $[23,24]$. The adsorption reactions for $\mathrm{C}_{6} \mathrm{H}_{6}, \mathrm{C}_{8} \mathrm{H}_{8}, \mathrm{C}_{5} \mathrm{H}_{8}$, and $\mathrm{C}_{6} \mathrm{H}_{12}$ gases on carbon nanotubes are calculated based on density functional theory (DFT); the sensitivity of carbon nanotubes for these gases was analyzed. We found that Ni doping remarkably improves the response sensitivity and cross-sensitivity.

\section{Computational Details}

In the paper, all the calculations were based on $\mathrm{Dmol}^{3}$ package in Materials Studio, a molecule dynamic simulation software. The intrinsic and Ni-doped $(8,0)$ SWCNTs models and breath gases gas molecules were built at this platform. In order to avoid interaction between adjacent carbon nanotubes, a periodic boundary model with lattice parameters $20 \AA \times 20 \AA \times 8.52 \AA$ was adopted in our work. The electronic structure calculations were carried out by spin-polarized density theory, and the PBE generalized gradient approximation (GGA) exchange-correlation function parameterized by Perdew et al. is employed to deal with the electronelectron exchange and correlation interactions. Moreover, the double numerical basis set plus polarization functions (DNP) are used. In order to ensure calculation accuracy, the energy threshold, maximum force, and self-consistent field convergence criteria were set as $2.72 \times 10^{-4} \mathrm{eV}, 5.44 \times$ $10^{-2} \mathrm{eV} / \AA$, and $2.72 \times 10^{-5} \mathrm{eV}$, respectively. Moreover, The Brillouin zone integrations are performed using a $1 \times 1 \times 2$ Monkhorst-Pack mesh in calculations, which is shown to be a good approximation for $(8,0)$ SWCNTs.
Based on intrinsic $(8,0)$ SWCNTs, the Ni doping was employed by replacing one carbon atom with a $\mathrm{Ni}$ atom. The intrinsic SWCNTs, Ni-SWCNTs, breath gases $\left(\mathrm{C}_{6} \mathrm{H}_{6}, \mathrm{C}_{8} \mathrm{H}_{8}\right.$, $\mathrm{C}_{5} \mathrm{H}_{8}$, and $\mathrm{C}_{6} \mathrm{H}_{12}$ ) were relaxed, respectively, to find the lowest energy structure, which is shown in Figure 1. Then a single breath gas molecule $\left(\mathrm{C}_{6} \mathrm{H}_{6}, \mathrm{C}_{8} \mathrm{H}_{8}, \mathrm{C}_{5} \mathrm{H}_{8}\right.$, and $\left.\mathrm{C}_{6} \mathrm{H}_{12}\right)$ was adsorbed on the surface of intrinsic SWCNTs and NiSWCNTs. We found that a significant improvement has been obtained by Ni doping compared to intrinsic SWCNTs, which is similar to the literature [19].

The gas-surface interaction can be described using the adsorption energy $E_{\text {ads }}$. The adsorption energy $\left(E_{\mathrm{ads}}\right)$ of the molecules adsorbed on Ni-doped SWCNTs is obtained from

$$
E_{\text {ads }}=E_{\text {surface/gas }}-E_{\text {surface }}-E_{\text {gas }} \text {. }
$$

$E_{\text {surface/gas }}$ is the total energy of molecules absorbed on Pd-doped SWCNTs. $E_{\text {surface }}$ represents the total energy of the carbon nanotube (intrinsic or Ni-doped SWCNTs) before adsorption. $E_{\text {gas }}$ stands for the energy of isolated molecules. If $E_{\text {ads }}<0$, the adsorption process is assumed to be exothermic and occur spontaneously. The topological charge density distribution is analyzed by the Mulliken population analysis [25]. The charge transfer $Q_{T}$ between gas molecule and surface is calculated using (2), which is in great relation with change in electrical conductance of SWCNTs, and can provide important information about the electronic responses of the system.

$$
Q_{T}=Q_{\text {adsorbed gas }}-Q_{\text {isolate gas }} \text {. }
$$

\section{Results and Discussion}

3.1. Geometric and Electronic Structures of SWCNTs, NiSWCNTs, and Lung Cancer Breath Gases. We begin our study by analyzing the relaxed geometric structure of intrinsic, Ni-doped $(8,0)$ zigzag SWCNTs, and lung cancer gases, which can be compared with the adsorption structure to study the impact of gas molecule adsorption. As can be seen in Figure 1(a), the bond lengths of C1-C2 and C1-C1 have the same value $1.44 \AA$ due to the symmetric structure, while the bond length of $\mathrm{C} 1-\mathrm{C} 4$ is $1.41 \AA$, which is relatively smaller than that of C1-C2. The carbon atoms of SWCNTs are mainly built by $\mathrm{sp}^{2}$ hybridization. Besides, a certain degree of $\mathrm{sp}^{3}$ is formed cause of the bend of the hexagonal grid structure. That is, the chemical bonds have both $\mathrm{sp}^{2}$ and $\mathrm{sp}^{3}$ hybridization state at the same time, and these overlapped p orbitals were formed in highly delocalized carbon $\pi$ bond among the surface of carbon nanotubes. These $\pi$ bonds provide a basis for interacting with conjugated molecule by noncovalent bond. For the doping of individual $\mathrm{Ni}$ atom as described in side-view Figure 1(b), the carbon atom $\mathrm{C} 1$ has been substituted by one $\mathrm{Ni}$ atom. After structural relaxation, we found that the single $\mathrm{Ni}$ atom evidently protrudes out of the tube wall because the radii of the $\mathrm{Ni}$ atom are larger than other carbon atoms [26]. The bond lengths Ni-C3 and NiC4 have been lengthened to $1.84 \AA$ and $1.76 \AA$, respectively, forming a tripod-like structure.

Upon the lung cancer breath gases, $\mathrm{C}_{6} \mathrm{H}_{6}$ is a planar molecule with all of the 12 contained atoms in the same 


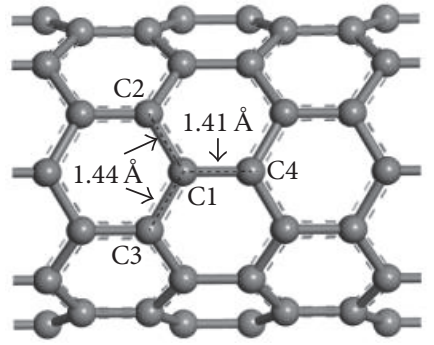

(a)

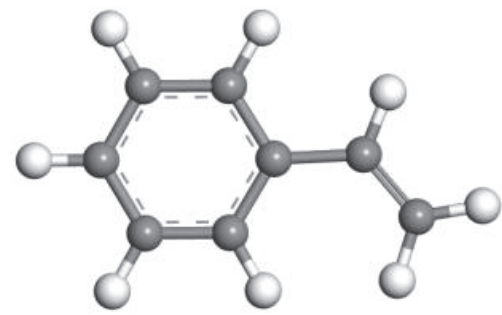

(d)

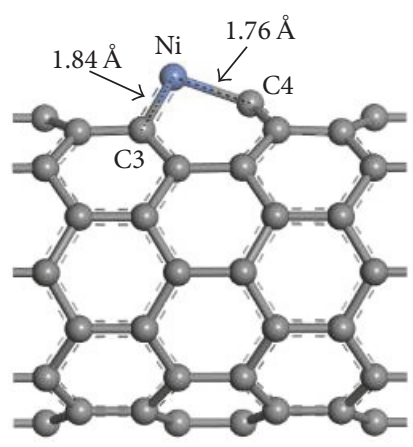

(b)

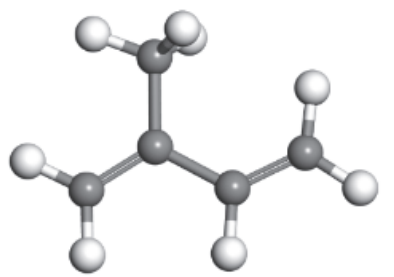

(e)

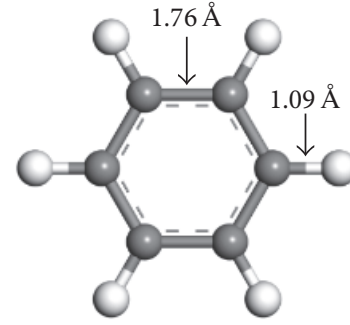

(c)

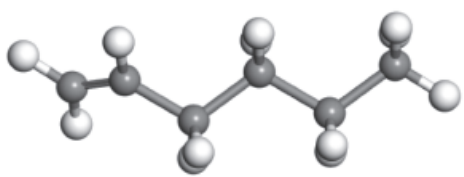

(f)

Figure 1: Optimized structures: (a) intrinsic SWCNTs, (b) Ni-SWCNTs, (c) $\mathrm{C}_{6} \mathrm{H}_{6}$, (d) $\mathrm{C}_{8} \mathrm{H}_{8}$, (e) $\mathrm{C}_{5} \mathrm{H}_{8}$, and (f) $\mathrm{C}_{6} \mathrm{H}_{12}$. Carbon atoms are denoted in gray, nickel atoms in blue, and hydrogen atoms in white.

TABLE 1: Adsorption energy $\left(E_{\text {ads }}\right)$, charge transfer $\left(Q_{T}\right)$, and the binding distance from the gases to Ni atom.

\begin{tabular}{|c|c|c|c|c|}
\hline System & Structure & $E_{\text {ads }}(\mathrm{eV})$ & $Q_{T}(\mathrm{e})$ & $d_{1}(\AA)$ \\
\hline $\mathrm{C}_{6} \mathrm{H}_{6} / \mathrm{SWCNTs}$ & Figure 2(al) & -0.044 & 0.003 & 3.63 \\
\hline $\mathrm{C}_{6} \mathrm{H}_{6} / \mathrm{Ni}-\mathrm{SWCNTs}$ & Figure 2(a2) & -0.756 & 0.241 & 2.35 \\
\hline $\mathrm{C}_{8} \mathrm{H}_{8} /$ SWCNTs & Figure 2(b1) & -0.047 & 0.004 & 2.56 \\
\hline $\mathrm{C}_{8} \mathrm{H}_{8} / \mathrm{Ni}$-SWCNTs & Figure 2(b2) & -1.163 & 0.023 & 2.01 \\
\hline $\mathrm{C}_{5} \mathrm{H}_{8} /$ SWCNTs & Figure 2(c1) & -0.021 & 0.002 & 3.72 \\
\hline $\mathrm{C}_{5} \mathrm{H}_{8} / \mathrm{Ni}-\mathrm{SWCNTs}$ & Figure 2(c2) & -1.098 & 0.097 & 2.07 \\
\hline $\mathrm{C}_{6} \mathrm{H}_{12} / \mathrm{SWCNTs}$ & Figure 2(d1) & -0.027 & -0.007 & 2.94 \\
\hline $\mathrm{C}_{6} \mathrm{H}_{12} / \mathrm{Ni}-\mathrm{SWCNTs}$ & Figure 2(d2) & -1.079 & 0.126 & 2.11 \\
\hline
\end{tabular}

plane. The C-C and C-H bond lengths are $1.76 \AA$ and $1.09 \AA$, respectively, which is consistent with previous research [27]. $\mathrm{C}_{8} \mathrm{H}_{8}$ is an organic compound with the chemical formula $\mathrm{C}_{6} \mathrm{H}_{5} \mathrm{CH}=\mathrm{CH}_{2}$, which is one derivative of $\mathrm{C}_{6} \mathrm{H}_{6} . \mathrm{C}_{8} \mathrm{H}_{8}$ is the monomer of polystyrene, and its derivatives are widely used polymers in organic light emitting devices (OLED) and field-effect transistors (FET) [28]. Williams et al. has studied the $\mathrm{C}_{8} \mathrm{H}_{8}$ adsorption on the Ag (llll) surface [29]. $\mathrm{C}_{5} \mathrm{H}_{8}$ is considered one of the most abundant endogenous hydrocarbons present in human breath air, especially in the breath gases of lung cancer patients. It has been detected by infrared photoacoustic spectroscopy and proton-transferreaction mass spectrometry $[25,30] . \mathrm{C}_{6} \mathrm{H}_{12}$ is an organic compound with the formula $\mathrm{C}_{6} \mathrm{H}_{12}$. It is an alkene that is classified as alpha-olefin with double bond located at the alpha position, endowing the compound with high reactivity properties.
3.2. Adsorption of $\mathrm{C}_{6} \mathrm{H}_{6}, \mathrm{C}_{8} \mathrm{H}_{8}, \mathrm{C}_{5} \mathrm{H}_{8}$, and $\mathrm{C}_{6} \mathrm{H}_{12}$ on the Surface of Intrinsic and Ni-Doped SWCNTs. In order to find the stable adsorption structure, the breath gas molecules are made to approach the surface of SWCNTs and Ni-SWCNTs in many different posture. The binding distance $d$ is defined as the nearest distance between the molecule and the surface. The adsorption energy $E_{\text {ads }}$, charge transfer $Q_{T}$, and binding distance $\mathrm{d}$ are presented in Table 1.

Figures 2(a1) and 2(a2) show the adsorption structures of single $\mathrm{C}_{6} \mathrm{H}_{6}$ molecule on intrinsic and Ni-doped SWCNTs surface. Upon intrinsic SWCNTs surface, the adsorption distance from $\mathrm{C}_{6} \mathrm{H}_{6}$ molecule to intrinsic SWCNTs reaches $3.63 \AA$, and the adsorption energy and charge transfer are only $0.044 \mathrm{eV}$ and $0.003 \mathrm{e}$, signifying that the adsorption between $\mathrm{C}_{6} \mathrm{H}_{6}$ and intrinsic SWCNTs is weak physisorption, while, upon $\mathrm{Ni}$-doped intrinsic SWCNTs surface, the protruding $\mathrm{Ni}$ atom acts as the active site to adsorb $\mathrm{C}_{6} \mathrm{H}_{6}$ molecule. After 


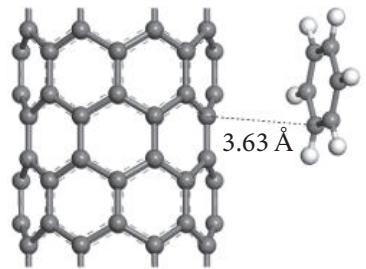

(a1)

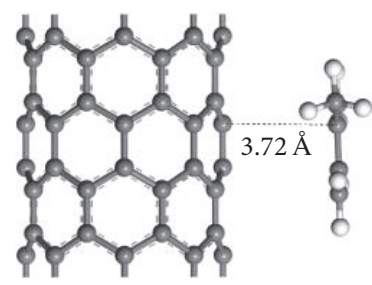

(c1)

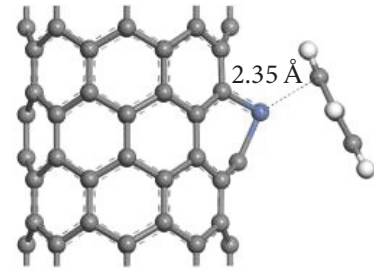

(a2)

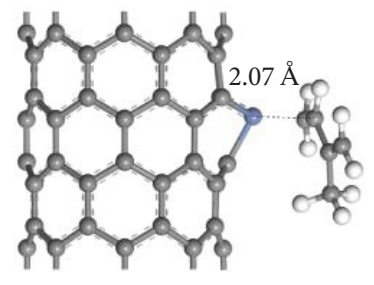

(c2)

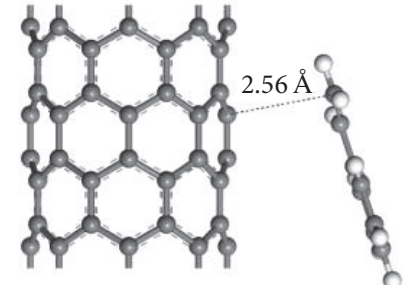

(b1)

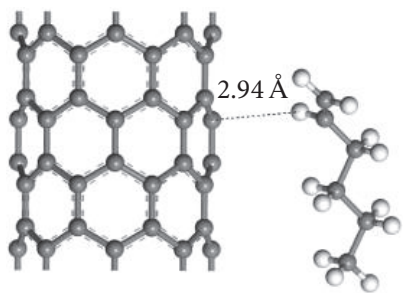

(d1)

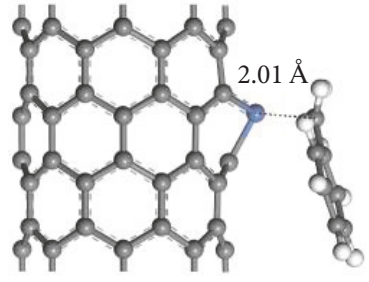

(b2)

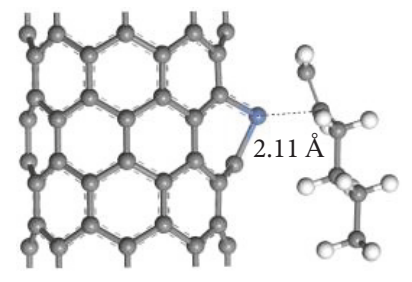

(d2)

Figure 2: Optimized geometry: (a1)-(d1) represent $\mathrm{C}_{6} \mathrm{H}_{6}, \mathrm{C}_{8} \mathrm{H}_{8}, \mathrm{C}_{5} \mathrm{H}_{8}$, and $\mathrm{C}_{6} \mathrm{H}_{12}$ on intrinsic SWCNTs; (a2)-(d2) represent $\mathrm{C}_{6} \mathrm{H}_{6}$, $\mathrm{C}_{8} \mathrm{H}_{8}$, $\mathrm{C}_{5} \mathrm{H}_{8}$, and $\mathrm{C}_{6} \mathrm{H}_{12}$ on Ni-SWCNTs.

structural relaxation optimization, the adsorption distance between $\mathrm{C}_{6} \mathrm{H}_{6}$ and $\mathrm{Ni}$ atom is $2.35 \AA$, which is distantly less than that between intrinsic SWCNTs and $\mathrm{C}_{6} \mathrm{H}_{6}$ molecule. In addition, the adsorption energy and charge transfer have increased to $-0.76 \mathrm{eV}$ and $0.241 \mathrm{e}$. By comparison, $\mathrm{Ni}$ doping distantly enhances the adsorption properties of SWCNTs to $\mathrm{C}_{6} \mathrm{H}_{6}$ molecule. According to the detection mechanism of gas sensors, the gas molecule must interact with gas sensing material if it needs to be detected. Therefore, the strong adsorption property between gas molecule and gas sensing material lays the foundation for gas the detection. In addition, the charge redistribution during gas adsorption will dramatically influence the conductivity of gas sensing material. Comparing with intrinsic SWCNTs, Ni-doped SWCNTs adsorption excites large electron transfer, leading to the change of conductivity of adsorption system.

In the case of $\mathrm{C}_{8} \mathrm{H}_{8}$ adsorption, the $\mathrm{C}_{8} \mathrm{H}_{8}$ molecule trends to react with the vinyl of the $\mathrm{C}_{8} \mathrm{H}_{8}$. After full relax optimization, the energetically stable states have obtained with configurations depicted in Figures 2(b1) and 2(b2). The react length has reached $2.56 \AA$ upon the molecule adsorbed on the intrinsic SWCNTs, which is obviously larger than that of Ni-SWCNTs adsorption length $(2.01 \AA)$. The $\mathrm{C}_{8} \mathrm{H}_{8}$ molecule is found to be weakly bound to the surface of the SWCNTs with a calculated adsorption energy of $0.047 \mathrm{eV}$, which is identical with the weak $Q_{T}(0.004 \mathrm{e})$. Nevertheless, for molecule adsorption on surface of Ni-SWCNTs, the adsorption energy and $Q_{T}$ have effectively increased to $-1.163 \mathrm{eV}$ and $0.023 \mathrm{e}$, respectively. Due to the enhanced adsorption interaction to the $\mathrm{C}_{8} \mathrm{H}_{8}$ molecule, the molecule has deformed with the vinyl out of the $\mathrm{C}_{6} \mathrm{H}_{6}$ ring of $\mathrm{C}_{8} \mathrm{H}_{8}$. According to the molecule adsorption structure, we conclude that the $\mathrm{C}_{8} \mathrm{H}_{8}$ molecule is physisorbed onto the surface of adsorbent with little or no reconstruction.

The adsorption results of $\mathrm{C}_{5} \mathrm{H}_{8}$ molecule on Ni-SWCNTs are presented in Figures 2(c1) and 2(c2) and Table 1. The calculated lengths of $\mathrm{C}_{5} \mathrm{H}_{8}$ adsorbed on the surface of adsorbent, intrinsic SWCNTs and Ni-SWCNTs are $3.72 \AA$ and $2.07 \AA$, and $Q_{T}$ is $0.002 \mathrm{e}$ and 0.097 e. $\mathrm{C}_{5} \mathrm{H}_{8}$ molecule prefers to adsorb with its carbon atom approach towards the carbon atoms of SWCNTs and Ni atom of the Ni-SWCNTs, the rest of the molecule position being parallel with the adsorbent surface. The long interaction distance indicated that the adsorption interaction is weak physisorption like the $\mathrm{C}_{6} \mathrm{H}_{6}$ and $\mathrm{C}_{8} \mathrm{H}_{8}$ adsorption. The further $E_{\text {ads }}$ calculation also confirmed this point; $E_{\text {ads }}$ of $\mathrm{C}_{6} \mathrm{H}_{6}$ is by exothermic -0.021 and $-1.098 \mathrm{eV}$. This weak adoption energy is not enough to break the covalent bond between hydrogen atom and carbon atom in $\mathrm{C}_{5} \mathrm{H}_{8}$ molecule.

We also investigated the influence of $\mathrm{Ni}$ atom doping to the adsorption of $\mathrm{C}_{6} \mathrm{H}_{12}$; the relaxed results are shown in Figures 2(d1) and 2(d2) and Table $1 . \mathrm{C}_{6} \mathrm{H}_{12}$ tends to bond with the adsorbent at the double bond site through carbon atom of $\mathrm{C}_{6} \mathrm{H}_{12}$. The optimized interaction length is about $2.94 \AA$ with interaction energy of $-0.027 \mathrm{eV}$, which allow the $\mathrm{C}_{6} \mathrm{H}_{12}$ molecule easy dissociation from the surface of intrinsic SWCNTs. Moreover, the $\mathrm{C}_{6} \mathrm{H}_{12}$ molecule is hardly to arouse the charge redistribution of the surface charges due to the weak interaction energy and long distance. Upon the $\mathrm{C}_{6} \mathrm{H}_{12}$ adsorption on the surface of Ni-SWCNTs, the adsorption energy and binding distance are $-1.079 \mathrm{eV}$ and $2.11 \AA$ with the $\mathrm{Ni}$ atom acting as the reaction site, which indicate the significant increment of physisorption. The gas adsorption triggered charge redistribution results in about $0.126 \mathrm{e}$ transfer from $\mathrm{C}_{6} \mathrm{H}_{12}$ molecule to the surface of $\mathrm{Ni}$ SWCNTs, which is distinctly larger than that of intrinsic SWCNTs adsorption.

3.3. Electronic Structure of the Intrinsic SWCNTs and NiSWCNTs upon Molecule Adsorption. To investigate the influence of breath gases on the electricity of intrinsic SWCNTs and Ni-SWCNTs, the total densities of stated (TDOS) and the 


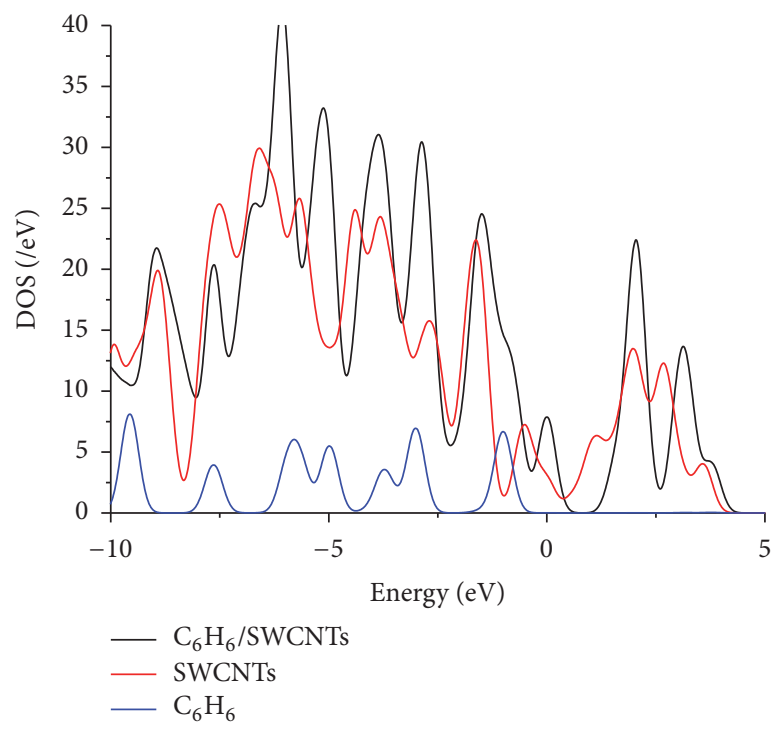

(a)

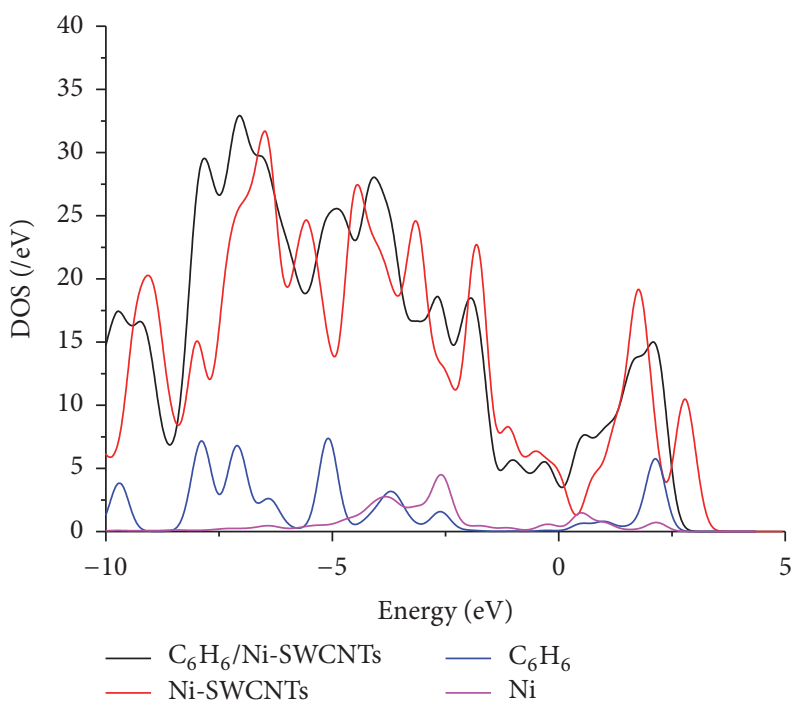

(b)

FIgure 3: (a) DOS of $\mathrm{C}_{6} \mathrm{H}_{6}$ adsorbed on SWCNTs surface; (b) DOS of $\mathrm{C}_{6} \mathrm{H}_{6}$ adsorbed on Ni-SWCNTs surface.

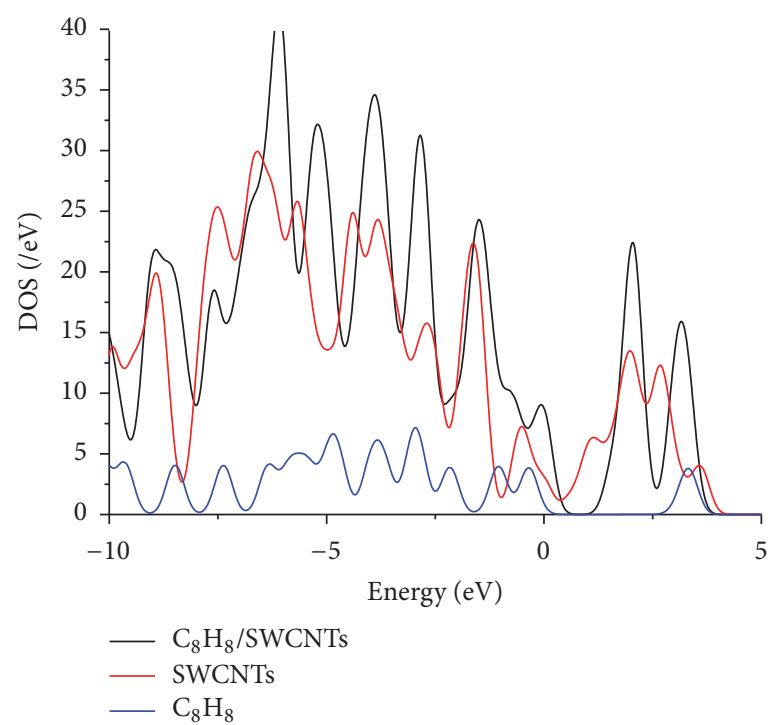

(a)

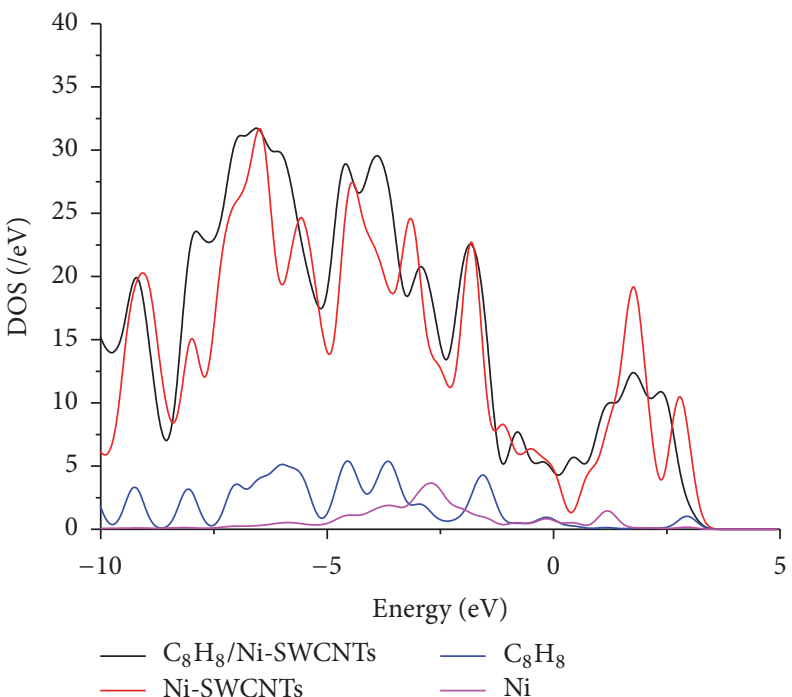

(b)

Figure 4: (a) DOS of $\mathrm{C}_{8} \mathrm{H}_{8}$ adsorbed on SWCNTs surface; (b) DOS of $\mathrm{C}_{8} \mathrm{H}_{8}$ adsorbed on Ni-SWCNTs surface.

partial DOS (PDOS) of gas adsorbed structures are calculated by DFT-PBE method with the Fermi level aligning at zero as depicted in Figures 3-6. Although the DFT-PBE method underestimates the band gap to a certain extent, it still provides correct features of electronic structure in general. Due to its validity and feasibility, it has been widely used to calculate the DOS change of gas sensing system during the gas sensing process. According to the strong correlation between DOS and electrical conductivity, we analyze the change of conductivity through the change of DOS.

As the change of DOS For $\mathrm{C}_{6} \mathrm{H}_{6}$ sensing shown in Figures 3(a) and 3(b), the TDOS near the Fermi level tends to be volatile especially below and above the Fermi level, where it is obviously decreased. The electrons are mainly located long above and below the Fermi level, indicating that only limited electrons can leap from valence band to conduction band. After single $\mathrm{Ni}$ atom is doped on the surface of SWCNTs, the DOS of Ni is distinctly enhanced because the metal $\mathrm{Ni}$ atom provides impurity level, which increases the electron transmission capability. When the $\mathrm{C}_{6} \mathrm{H}_{6}$ molecule adsorbs on the surface of Ni-SWCNTs, part of the electron of $\mathrm{C}_{6} \mathrm{H}_{6}$ transfers from gas molecules to Ni-SWCNTs, and these electrons are mainly located at the $\mathrm{Ni}$ atom doped site. As a result, the TDOS is uniformly distributed around the 


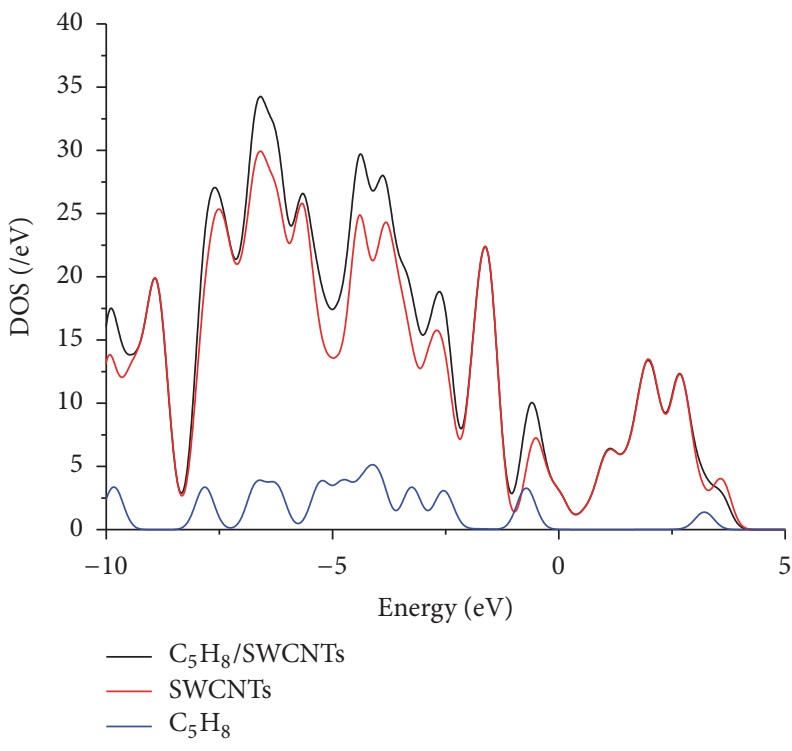

(a)

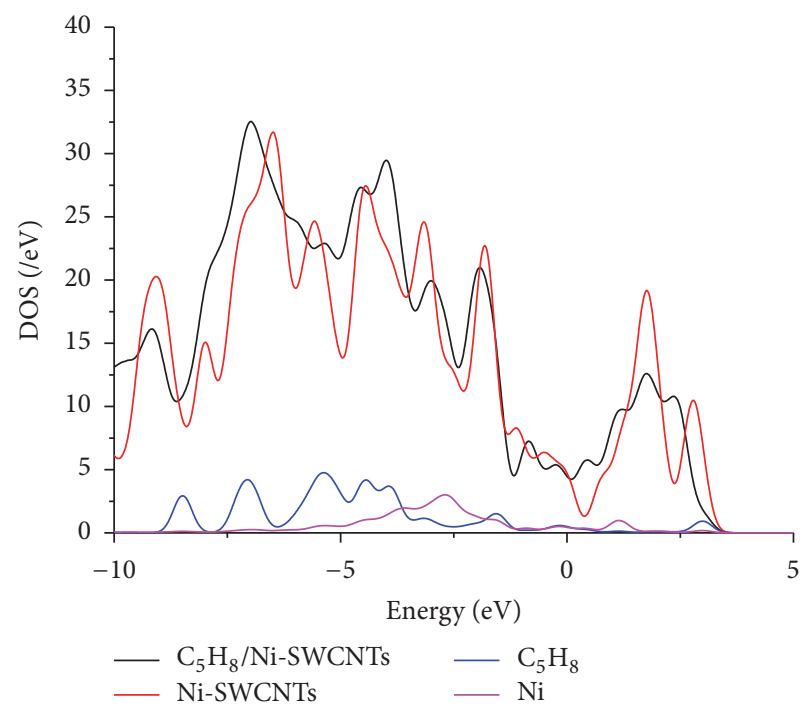

(b)

Figure 5: (a) DOS of $\mathrm{C}_{5} \mathrm{H}_{8}$ adsorbed on SWCNTs surfaces; (b) DOS of $\mathrm{C}_{5} \mathrm{H}_{8}$ adsorbed on Ni-SWCNTs surfaces.

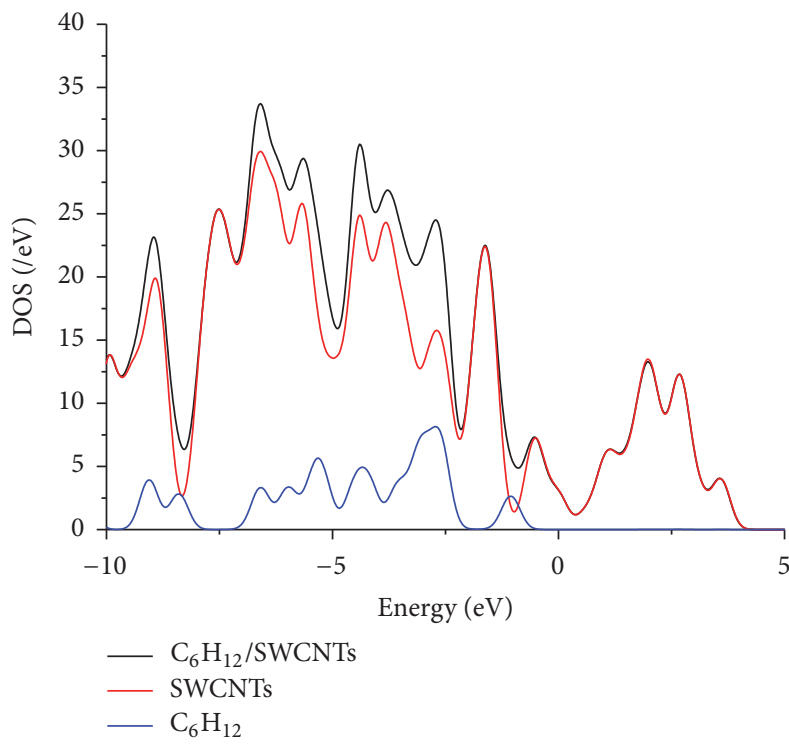

(a)

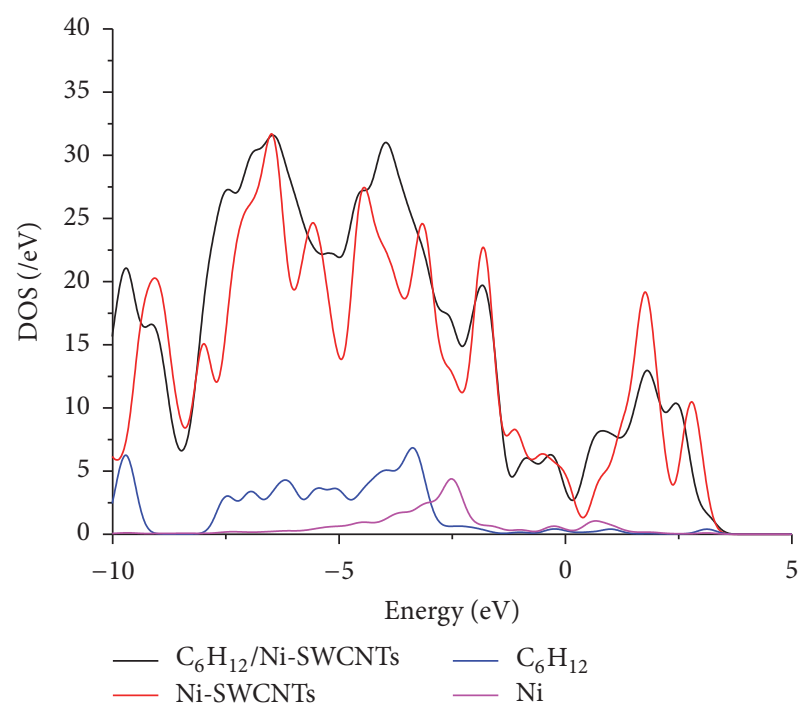

(b)

Figure 6: (a) DOS of $\mathrm{C}_{6} \mathrm{H}_{12}$ adsorbed on SWCNTs surface; (b) DOS of $\mathrm{C}_{6} \mathrm{H}_{12}$ adsorbed on Ni-SWCNTs surface.

Fermi level, which effectively improves the conductivity by enhancing the electron transition probability.

Figures 4(a) and 4(b) show the change of DOS for $\mathrm{C}_{8} \mathrm{H}_{8}$ adsorbed on intrinsic SWCNTs and Ni-SWCNTs. When $\mathrm{C}_{8} \mathrm{H}_{8}$ molecules adsorb on the surface of intrinsic SWCNTs, the increase of DOS is mainly located below Fermi level, while it brings nearly no contribution to the electron distribution at or above Fermi level. In consequence, the conductivity of SWCNTs changes little during $\mathrm{C}_{8} \mathrm{H}_{8}$ detection; namely, SWCNTs material is insensitive to $\mathrm{C}_{8} \mathrm{H}_{8}$. The metal Ni atom active site provides strong interaction with vinyl, leading to the electron transfer from $\mathrm{C}_{8} \mathrm{H}_{8}$ gas molecules to $\mathrm{Ni}$ SWCNTs. It is found that the DOS at the Fermi level obviously increases upon $\mathrm{C}_{8} \mathrm{H}_{8}$ adsorption.

Similarly, the Ni doping method shows the same effect to the adsorption of and $\mathrm{C}_{5} \mathrm{H}_{8}$ molecules as shown in Figure 5. When single $\mathrm{C}_{5} \mathrm{H}_{8}$ molecule adsorbs on intrinsic SWCNTs, the increased DOS is mainly distributed below the Fermi level, and the DOS at and above the Fermi level nearly does not change. When the target $\mathrm{C}_{5} \mathrm{H}_{8}$ molecules approach and react with the sidewall surface of Ni-SWCNTs, the TDOS has distinctly increased at the Fermi level. Comparing the change 
of DOS for different gas molecules adsorption, the increment of TDOS for $\mathrm{C}_{6} \mathrm{H}_{12}$ adsorption on Ni-SWCNTs is the least because of the weak interaction as shown in Figure 6. Due to the change of conductivity, Ni-SWCNTs is proved to be an outstanding gas sensing material to detect the breath gases: $\mathrm{C}_{6} \mathrm{H}_{6}, \mathrm{C}_{8} \mathrm{H}_{8}, \mathrm{C}_{5} \mathrm{H}_{8}$, and $\mathrm{C}_{6} \mathrm{H}_{12}$.

\section{Conclusion}

An ab initio study has been presented to investigate the adsorption of typical lung cancer breath gases onto the surface of intrinsic and Ni-doped $(8,0)$ SWCNTs. The target gas molecules have been made to approach the adsorbent by diversity postures to find the most stable adsorption configurations. It is found that the adsorption of target gases is an exothermic process and occurs spontaneously. The adsorption energy, charge transfer, and DOS have been evaluated in this work.

According to the results, $\mathrm{C}_{6} \mathrm{H}_{6}, \mathrm{C}_{8} \mathrm{H}_{8}, \mathrm{C}_{5} \mathrm{H}_{8}$, and $\mathrm{C}_{6} \mathrm{H}_{12}$ are adsorbed onto the sidewall surface of intrinsic SWCNTs by weak physisorption with nearly no charge transfer; thus SWCNTs are not suitable for breath gases detection of lung cancer. After the doping of $\mathrm{Ni}$ atom, the adsorption energy and charger transfer have distinctly increased with the corresponding DOS enhanced around the Fermi level, leading to the increase of conductivity of adsorption structures. Therefore, Ni-SWCNTs would be used to develop portable electrochemical sensor by detecting the typical lung cancer breath gases. Our finding will be helpful for future experimental study on metal doped SWCNTs systems for lung cancer diagnosis.

\section{Conflicts of Interest}

The authors declare that they have no conflicts of interest.

\section{References}

[1] M. Hakim, Y. Y. Broza, O. Barash et al., "Volatile organic compounds of lung cancer and possible biochemical pathways," Chemical Reviews, vol. 112, no. 11, pp. 5949-5966, 2012.

[2] A. Jemal, F. Bray, M. M. Center, J. Ferlay, E. Ward, and D. Forman, "Global cancer statistics," CA: A Cancer Journal for Clinicians, vol. 61, no. 2, pp. 69-90, 2011.

[3] Y. Guo, H. Zeng, R. Zheng et al., "The association between lung cancer incidence and ambient air pollution in China: A spatiotemporal analysis," Environmental Research, vol. 144, article no. 6658, pp. 60-65, 2016.

[4] L. Hutchinson, "Screening: Improved model for lung cancer detection," Nature Reviews Clinical Oncology, vol. 10, no. 4, p. $183,2013$.

[5] R. F. Machado, D. Laskowski, O. Deffenderfer et al., "Detection of lung cancer by sensor array analyses of exhaled breath," American Journal of Respiratory and Critical Care Medicine, vol. 171, no. 11, pp. 1286-1291, 2005.

[6] A. Bajtarevic, C. Ager, M. Pienz et al., "Noninvasive detection of lung cancer by analysis of exhaled breath," BMC Cancer, vol. 9, article 348, 2009.
[7] P. J. Mazzone, J. Hammel, R. Dweik et al., "Diagnosis of lung cancer by the analysis of exhaled breath with a colorimetric sensor array," Thorax, vol. 62, no. 7, pp. 565-568, 2007.

[8] M. Phillips, K. Gleeson, J. M. B. Hughes et al., "Volatile organic compounds in breath as markers of lung cancer: a crosssectional study," The Lancet, vol. 353, no. 9168, pp. 1930-1933, 1999.

[9] M. Phillips, R. N. Cataneo, A. R. C. Cummin et al., "Detection of lung cancer with volatile markers in the breath," Chest, vol. 123, no. 6, pp. 2115-2123, 2003.

[10] B. Thekedar, Investigations on the Use of Breath Gas Analysis with Proton Transfer Reaction Mass Spectrometry (PTR-MS) for a Non-Invasive Method of Early Lung Cancer Detection, Acta Geodaetica Et Cartographic Sinica, 2009.

[11] A. V. Rutter, T. W. E. Chippendale, Y. Yang, P. Španěl, D. Smith, and J. Sulé-Suso, "Quantification by SIFT-MS of acetaldehyde released by lung cells in a 3D model," The Analyst, vol. 138, no. 1, pp. 91-95, 2013.

[12] W. Filipiak, A. Sponring, A. Filipiak et al., "TD-GC-MS analysis of volatile metabolites of human lung cancer and normal cells in vitro," Cancer Epidemiology Biomarkers and Prevention, vol. 19, no. 1, pp. 182-195, 2010.

[13] H. Zeng, A. McWilliams, and S. Lam, "Optical spectroscopy and imaging for early lung cancer detection: a review," Photodiagnosis and Photodynamic Therapy, vol. 1, no. 2, pp. 111-122, 2004.

[14] N. L. W. Septiani and B. Yuliarto, "Review-the development of gas sensor based on carbon nanotubes," Journal of the Electrochemical Society, vol. 163, no. 3, pp. B97-B106, 2016.

[15] T. Zhang, S. Mubeen, N. V. Myung, and M. A. Deshusses, "Recent progress in carbon nanotube-based gas sensors," Nanotechnology, vol. 19, no. 33, Article ID 332001, 2008.

[16] Y. Lu, J. Li, J. Han et al., "Room temperature methane detection using palladium loaded single-walled carbon nanotube sensors," Chemical Physics Letters, vol. 391, no. 4-6, pp. 344-348, 2004.

[17] M. Penza, G. Cassano, R. Rossi et al., "Enhancement of sensitivity in gas chemiresistors based on carbon nanotube surface functionalized with noble metal (Au, Pt) nanoclusters," Applied Physics Letters, vol. 90, no. 17, Article ID 173123, 2007.

[18] L. Meng, J. Jin, G. X. Yang, T. H. Lu, H. Zhang, and C. X. Cai, "Nonenzymatic electrochemical detection of glucose based on palladium-single-walled carbon nanotube hybrid nanostructures," Analytical Chemistry, vol. 81, no. 17, pp. 7271-7280, 2009.

[19] J. Lu, X. Zhang, X. Wu, Z. Dai, and J. Zhang, "A Ni-doped carbon nanotube sensor for detecting oil-dissolved gases in transformers," Sensors (Switzerland), vol. 15, no. 6, pp. 1352213532, 2015.

[20] X. Zhang, H. Cui, Y. Gui, and J. Tang, "Mechanism and Application of Carbon Nanotube Sensors in SF6 Decomposed Production Detection: a Review," Nanoscale Research Letters, vol. 12, no. 1, 2017.

[21] M. L. Terranova, M. Lucci, S. Orlanducci et al., "Carbon nanotubes for gas detection: Materials preparation and device assembly," Journal of Physics Condensed Matter, vol. 19, no. 22, Article ID 225004, 2007.

[22] R. Leghrib, A. Felten, F. Demoisson, F. Reniers, J.-J. Pireaux, and E. Llobet, "Room-temperature, selective detection of benzene at trace levels using plasma-treated metal-decorated multi-walled carbon nanotubes," Carbon, vol. 48, no. 12, pp. 3477-3484, 2010.

[23] X. Chen, M. Cao, Y. Li et al., "A study of an electronic nose for detection of lung cancer based on a virtual SAW gas sensors 
array and imaging recognition method," Measurement Science and Technology, vol. 16, no. 8, pp. 1535-1546, 2005.

[24] X. Chen, F. Xu, Y. Wang et al., "A study of the volatile organic compounds exhaled by lung cancer cells in vitro for breath diagnosis," Cancer, vol. 110, no. 4, pp. 835-844, 2007.

[25] J. Taucher, A. Hansel, A. Jordan, R. Fall, J. H. Futrell, and W. Lindinger, "Detection of isoprene in expired air from human subjects using proton-transfer-reaction mass spectrometry," Rapid Communications in Mass Spectrometry, vol. 11, no. 11, pp. 1230-1234, 1997.

[26] X. Zhang, Y. Gui, H. Xiao, and Y. Zhang, "Analysis of adsorption properties of typical partial discharge gases on Ni-SWCNTs using density functional theory," Applied Surface Science, vol. 379, pp. 47-54, 2016.

[27] F. Tournus and J.-C. Charlier, "Ab initio study of benzene adsorption on carbon nanotubes," Physical Review B, vol. 71, no. 16, Article ID 165421, 2005.

[28] W. Wei, W. X. Huang, and J. M. White, "Adsorption of styrene on Ag(111)," Surface Science, vol. 572, no. 2-3, pp. 401-408, 2004.

[29] F. J. Williams, D. P. C. Bird, E. Charles, H. Sykes, A. K. Santra, and R. M. Lambert, "Molecular conformation of styrene on $\operatorname{Ag}(100)$ : Relevance to an understanding of the catalytic epoxidation of terminal alkenes," Journal of Physical Chemistry B, vol. 107, no. 16, pp. 3824-3828, 2003.

[30] F. Kühnemann, M. Wolfertz, S. Arnold et al., "Simultaneous online detection of isoprene and isoprene-d2 using infrared photoacoustic spectroscopy," Applied Physics B: Lasers and Optics, vol. 75, no. 2-3, pp. 397-403, 2002. 


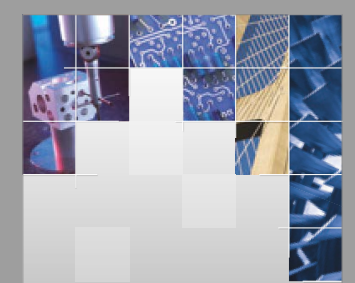

\section{Enfincering}
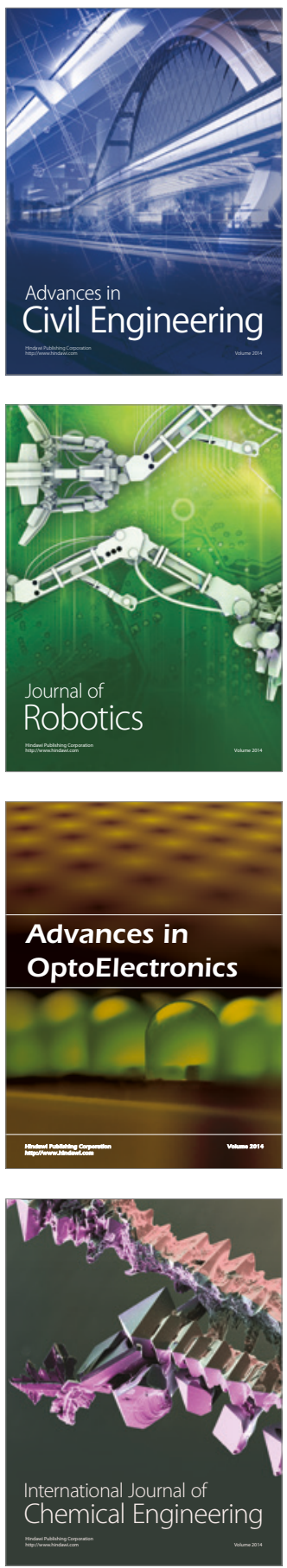

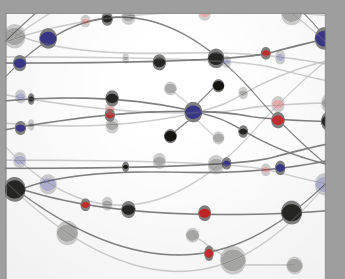

The Scientific World Journal

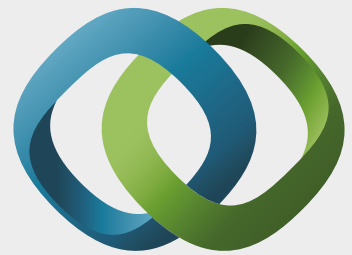

\section{Hindawi}

Submit your manuscripts at

https://www.hindawi.com
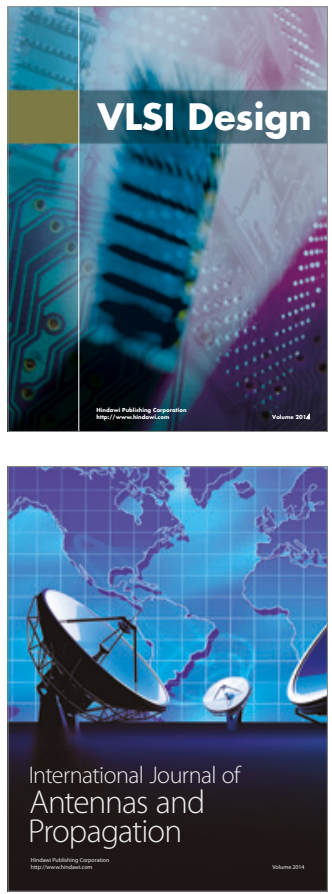

\section{Rotating}

Machinery
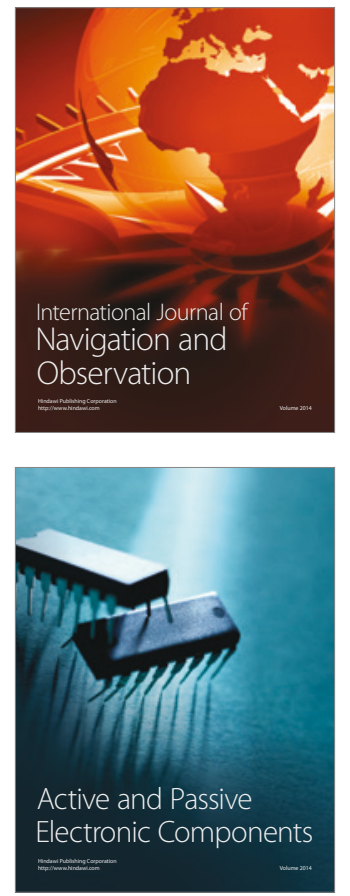
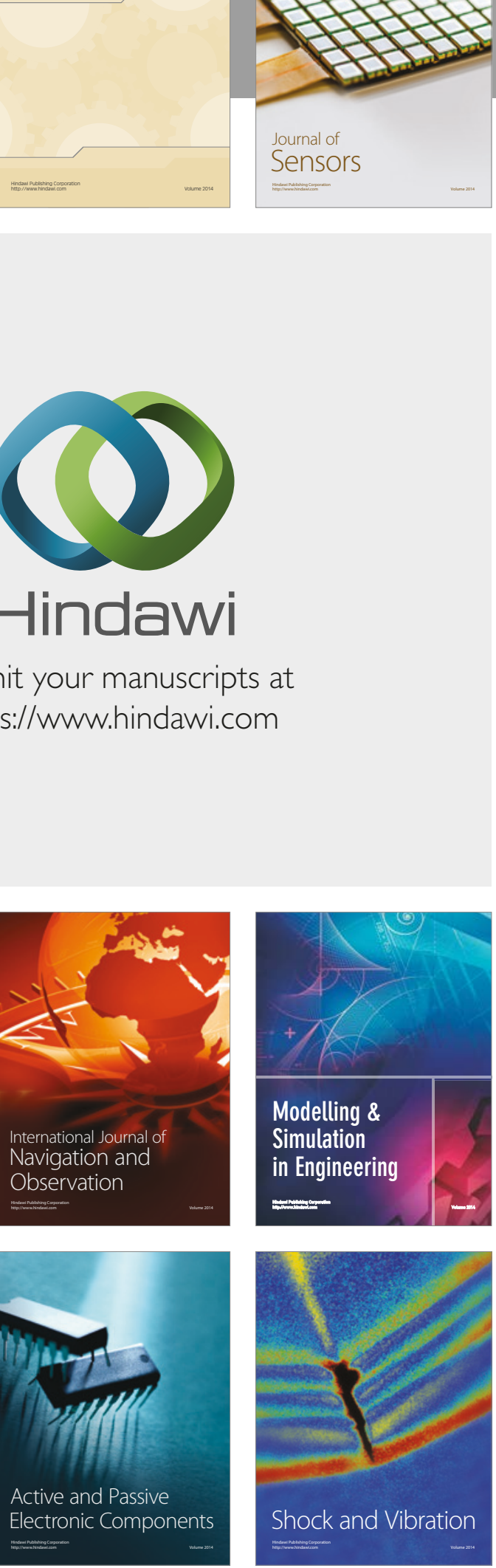
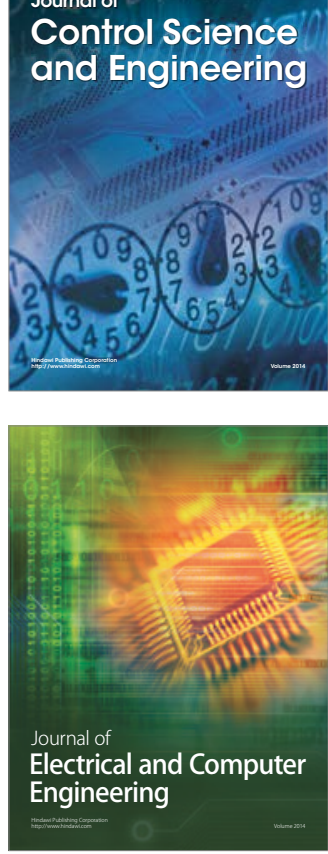

Distributed

Journal of

Control Science

and Engineering
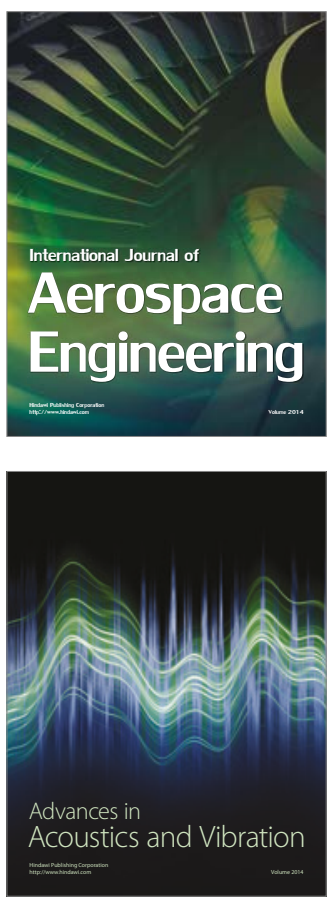

Sensor Networks 